\title{
Modeling competence in science education
}

Mei-Hung Chiu ${ }^{1^{*}}$ and Jing-Wen Lin $^{2}$

\begin{abstract}
Research on the understanding of the nature of models and modeling processes in science education have received a lot of attention in science education. In this article, we make five claims about the research on modeling competence in science education. The five claims are (1) the development of modeling competence in practice is essential to scientific literacy for twenty-first century citizens, (2) further research is needed to build a holistic and theoretical understanding of models and modeling knowledge (MMingK), (3) providing a modeling-based scaffolding framework for meaningful and active authentic learning is to enhance student's engagement of scientific practice, (4) appropriate formative assessment instruments and evaluation rubrics to assess students' modeling processes and products within the context of modeling practice should be developed, and (5) research on learning progression in modeling competence needs to be intertwined with MMingK and modeling practice. Implications for student learning and teacher professional development will be drawn from existing literature.
\end{abstract}

Keywords: Model, Modeling, Competence, Scientific literacy, Assessment

\section{Introduction}

In the last three decades, researchers in science education have been interested in understanding 1) how scientists used models to develop their scientific work, 2) what students' and teachers' perceptions of models are, 3) what the roles of models and modeling in science teaching and learning are, and 4) how to define, develop, and assess modeling competence. Accordingly, researchers have provided various definitions for models, modeling processes, model- or modeling-based instruction, and modeling practice (e.g., Clement \& Rea-Ramirez, 2008; Schwarz et al., 2009). Although there were variations in the definitions of these terms, they highlighted the importance of developing such competences and urged for effective assessment instruments to evaluate these competences (e.g., Namdar \& Shen, 2015; Nicolaou \& Constantinou, 2014).

For the model-based view, it emphasizes on understanding the concept of the theoretical model as well as the scope and limitations of scientific models (i.e., Justi \& Gilbert, 2002). "Exponents of model-based approaches believe that a re-interpretation of scientific theories as sets of models is more successful for an understanding of scientific theorizing" (Suppe, 1977, p. 221, cited from

\footnotetext{
* Correspondence: mhchiu@gapps.ntnu.edu.tw

'Graduate Institute of Science Education, National Taiwan Normal University, 88 Sec 4, Ting-Chou Road, Taipei, Taiwan

Full list of author information is available at the end of the article
}

Develaki, 2007, p. 729). In science learning, a model is said to be a representation of a target (e.g., Giere, Bickle, \& Maudlin, 2006; Grosslight, Unger, Jay, \& Smith, 1991), an analogy to bridge the source to the target (e.g., Treagust, Chittleborough, \& Mamiala, 2004), and a tool used to facilitate conceptual understanding, problem solving, or predicting phenomena (e.g., Clement \& ReaRamirez, 2008; Justi \& Gilbert, 2002). A model is also a representation that abstracts and simplifies a system by focusing on key features to explain and predict scientific phenomena (Schwarz et al., 2009). The models can fulfil not only interpretive and predictive functions, but also inventive functions (Halloun, 2004), in the sense that they work "... as an analogue for the construction of new application" (Adúriz-Bravo \& Izquierdo-Aymerich, 2005, p. 35; Halloun, 2004, p. 24, 62; cited in Develaki, p. 732). Given their varied emphases, models can be an internal or external representation of an observable event, object, or a phenomenon. They are viewed as complex systems that can be visual, mathematical, or analogical representations with feature resemblance to that phenomenon and also provide descriptive, explanatory, and predictive power. Researchers found that various model-based instructional techniques could cultivate students' and teachers' perceptions of models (such as computer modeling, e.g., Sins, Savelsbergh, van Joolingen, \& van Hout-Wolters, 2009). However, teachers were not well prepared in employing 
such a strategy (Oh \& Oh, 2011; van Driel, Bulte, \& Verloop, 2007).

As for the modeling-based view, it refers to the focus on the construction and refinement of scientific models and how teaching-learning processes relate to the construction of mental models (i.e., Nicolaou \& Constantinou, 2014). Modeling can provide the context in which the construction and refinement of models can achieve better quality outcomes than currently possible through other learning environments/tools (Louca, Zacharia, \& Constantinou, 2011). By engaging in such contexts, students are able to develop sense-making models that can help them internalize and attain epistemological sophistication of their understanding of the phenomenon investigated (Schwarz et al., 2009; Schwarz \& White, 2005).

The ubiquity of models in the history and current practice of science is widely recognized; indeed, it is difficult to think of science without models (Matthews, 2007). In science education, it is important to provide opportunities to teachers and students to understand how scientists work, how science investigations are carried out, and how phenomenon can be presented, delivered, and interpreted via the use of scientific models. In the following sections, we will make five claims to lead our discussions on the role of models and modeling process in science education practice.

\section{Claim 1: The development of modeling competence is essential to scientific literacy for the twenty-first century citizens}

Science is the process of constructing, describing, and explaining predictive conceptual models of natural phenomena (Gilbert, 1991; Schwarz et al., 2009). It is viewed as a complex and dynamic network of models, which are the core components of any scientific theory and take a central role in the formation and justification of knowledge (Koponen, 2007). During the processes, scientists present their thinking and problem solving competence on constructing, evaluating, and modifying their scientific models for their work. Recognizing the importance of building and revising models, there is an emerging call in science education to cultivate students' competence in understanding models and modeling knowledge, and experiencing modeling practices to elicit students' scientific literacy.

\section{Modeling competence}

In schools, modeling competence is considered as integral parts of scientific literacy (e.g., Gilbert \& Justi, 2016; Louca \& Zacharia, 2012). Practices of modeling researchers identified include having students (1) construct models consistent with prior evidence and theories to illustrate, explain, or predict phenomena, (2) use models to illustrate, explain, and predict phenomena, (3) compare and evaluate the ability of different models to accurately represent and account for patterns in phenomena, and to predict new phenomena, (4) revise models to increase their explanatory and predictive power, taking into account additional evidence or aspects of a phenomenon, and (5) understand the utility of multiple models of the same phenomenon or object (e.g., Gilbert \& Justi, 2016; Metcalf, Krajcik, \& Soloway, 2000; Schwarz et al., 2009). Based upon a systematic review of the existing citations, Nicolaou and Constantinou (2014) further identified modeling competence as modeling practices and metaknowledge. The former includes creating, revising, comparing, validating, and using models in practice; while the latter refers to metamodeling knowledge (the purpose and use of models), and metacognitive knowledge of the modeling process. Meta-knowledge includes meta-cognitive knowledge about the modeling process, which refers to students' ability to explicitly describe and reflect on the actual process of modeling (Nicolaou \& Constantinou, 2014). It also includes meta-modeling knowledge (mainly based upon Schwarz's work, such as Schwarz et al., 2009; Schwarz \& White, 2005), which is the "epistemological awareness about the nature and purpose of models" (Nicolaou \& Constantinou, 2014, p. 53). In addition to developing the competence about the use of these modeling processes, an individual should also develop their planning, monitoring, executing, and evaluating abilities on modeling practice. They should also try to strengthen their modeling competence in terms of the quality of their models and modeling knowledge (MMingK), so as to meet the needs of the new era.

As for the product of modeling practice, there should be visible, concrete products that can demonstrate students' modeling knowledge and abilities; this is relatively easy if the criteria for evaluating models were established (Pluta, Chinn, \& Duncan, 2011). However, there is a lack of deep discussions on the topics of modeling products. As part of its definition of modeling competence, only a limited number of studies included modeling "products" (if any, there were implicit) or even assessment of quality of the products in the modeling practices. For instance, in a systemic review of 104 empirical studies on modeling instruction in K-12 between 1980 and 2013, Namdar and Shen (2015) were only able to identified 15 articles that are related to the assessment of modeling products (e.g., Gobert, 2000; Louca et al., 2011; Sun \& Looi, 2013). Namdar and Shen (2015) proposed three aspects to assess models, namely, quality of model construct, representation, and coherence of a model as a whole. These might make clear as to what constitutes as a sound modeling product.

While researchers used terms (such as processes, products, and practice discussed above) interchangeably which create confusions of the emphasis of the studies 
on models and modeling in science, we propose modeling competence as including three aspects (see Fig. 1): MMingK, practice, and metacognitive knowledge of models and modeling in science learning in which MMingK refers to knowledge of models and modeling (including the use and function of models), metacognitive knowledge of models and modeling refers to the awareness of modeling processes, and in particular, practice including not only the processes but also the products of the modeling practices, both should be distinct and differentiated by teachers, students, as well as researchers.

\section{Curriculum standards}

There is also an increasing interest in investigating the value of models and modeling practice and products at the national level (Ministry of Education in Taiwan, 2018; NGSS Lead States, 2013). Taking NGSS as an example, it is clearly indicated that it is important to engage students in modeling activities and encourage students to reflect on the status of their own knowledge and their understanding of how science works. Curricula will need to stress the role of models explicitly and provide students with modeling tools so that they can come to value this core practice and develop a level of facility in constructing and applying appropriate models. The emphasis on modeling is also new and will need to be an explicit element of teacher preparation (NGSS Lead States, 2013). Similarly, in Taiwan, the newly released curriculum for grades 1-12 (Ministry of Education in Taiwan, 2018) stated that students are expected to develop inquiry competence in which constructing models to describe observations of physical phenomenon and understanding the limitation of scientific models are required for all grades. The higher the grades, the higher the level of modeling competences are required. A learning progression (LP) for understanding modeling competence could allow or even help students' understanding of models to gradually transform from seeing them as concrete objects or in absolute terms, to being able to revise models based on authoritative information, followed by attaining the ability to modify models based on evidence, before finally approaching models from the perspective of increasing explanatory power of the investigated phenomenon (NGSS Lead States, 2013).

As the world comes to see the development of scientific literacy as crucial and valuable for the new era, modeling competence has also emerged as one of the important and necessary components of scientific literacy. In the following sections, we will address the other four claims to indicate our positions about the enterprise of research in models and modeling. This includes understanding models and modeling knowledge (MMingK, see Claim 2), putting knowledge of models and modeling into practice via modeling processes (process; see Claim 3), and constructing internal and external products of the modeling practice (product; see Claim 4). These modeling competence elements should be evaluated via various channels and strategies (see Claim 5).

Claim 2: Further research is needed to build a holistic and theoretical understanding of models and modeling knowledge

The importance and path to move students toward scientific thinkers and to develop model-based view and

\begin{tabular}{|c|c|c|c|c|}
\hline & \multicolumn{2}{|c|}{ Modeling Competence } & & \\
\hline $\begin{array}{l}\text { Models and Modeling } \\
\text { Knowledge } \\
\text { - Ontology } \\
\text { - entity, properties } \\
\text { - Epistemology } \\
\text { - representations, value } \\
\text { - Methodology } \\
\text { - function, purpose, use }\end{array}$ & $\begin{array}{l}\text { Practice } \\
\text { Processes } \\
\text { - Development } \\
\text { - Elaboration } \\
\text { - Application } \\
\text { - Reconstruction }\end{array}$ & $\begin{array}{c}\mathbb{1} \\
\text { Product } \\
\bullet\end{array}$ & $\begin{array}{l}\text { Internal representations } \\
\text { (e.g., mental models - } \\
\text { from intuitive to } \\
\text { scientific models) } \\
\text { External representations } \\
\text { (e.g., physical objects or } \\
\text { drawings) }\end{array}$ & $\begin{array}{l}\text { Metacognitive } \\
\text { Knowledge of Models } \\
\text { and Modeling } \\
\text { - Planning } \\
\text { - Monitoring } \\
\text { - Executing } \\
\text { - Evaluating }\end{array}$ \\
\hline
\end{tabular}


modeling-based practice have been investigated by researchers from different disciplines over the past decades. Philosophers are generally concerned with the relationships, or logical operations, between models and theories, or between models and target systems, depending on their understanding of MMingK (Giere et al., 2006; Gilbert \& Justi, 2016). Meanwhile, psychologists are interested in how mental models are created, manipulated, evaluated, and used when one thinks about a target system (Nersessian, 2008). As stated earlier, there were various ways to investigate MMingK in science learning and teaching. However, most of the studies only examined MMingK from philosophical, historical, or psychological perspectives rather than from a more holistic perspective. Through a review of the existing literature, three aspects of MMingK are proposed for constructing the framework to understand MMingK, namely ontology, epistemology, and methodology (Fig. 2).

Taken Kuhn's paradigm as an example, Kuhn defined the meaning of paradigm as "universally recognized scientific achievements that, for a time, provide model problems and solutions for a community of researchers," (Kuhn, 1996, p. X). Halloun (1996) elaborated about the nature of the scientific paradigm that consisted of (1) ontological tenets about physical realities, (2) epistemological tenets that underlie the nature of various conceptions that make up any scientific theory, and (3) specific methodology (p. 16). While Taber (2009, p. 54) further explicitly depicted ontology as about the nature of the world in which we live, and epistemology is about how we come to have knowledge of that world, an (ontological) assumption that there is an objective world to know does not imply a(n) (epistemological) commitment to the possibility of obtaining true knowledge of that world. Appropriate methodology should be chosen for serving specific purposes of research. These aspects of ontology, epistemology, and methodology had shed some light on our understanding of the nature of models and modeling. In this section, we will discuss how these three pillars establish the theoretical framework of our research on models and modeling.

\section{Ontological perspective}

What specifically do we mean by models? Giere et al. (2006) depicted models as a family or population of models that share similar characteristics, emphasizing the structural and mapping relationships at different levels of similarity. In science education, an analogy can serve as a model to infer from better-known situations to a less familiar one. From the analysis of historical documents, researchers argued that scientists have often used various analogical models to help them develop theories and shift scientific paradigms in their work (Gentner \& Smith, 2012; Nersessian, 2008). Moreover, all models share some commonalities in that a model is considered a representation of a phenomenon, an object, an event, a concept, a mixture of entities, a device, a theory, or even a system either in a concrete form or a composition of abstractions for different purposes in science education (e.g., Everett, Otto, Luera, et al., 2009; Treagust et al., 2004).

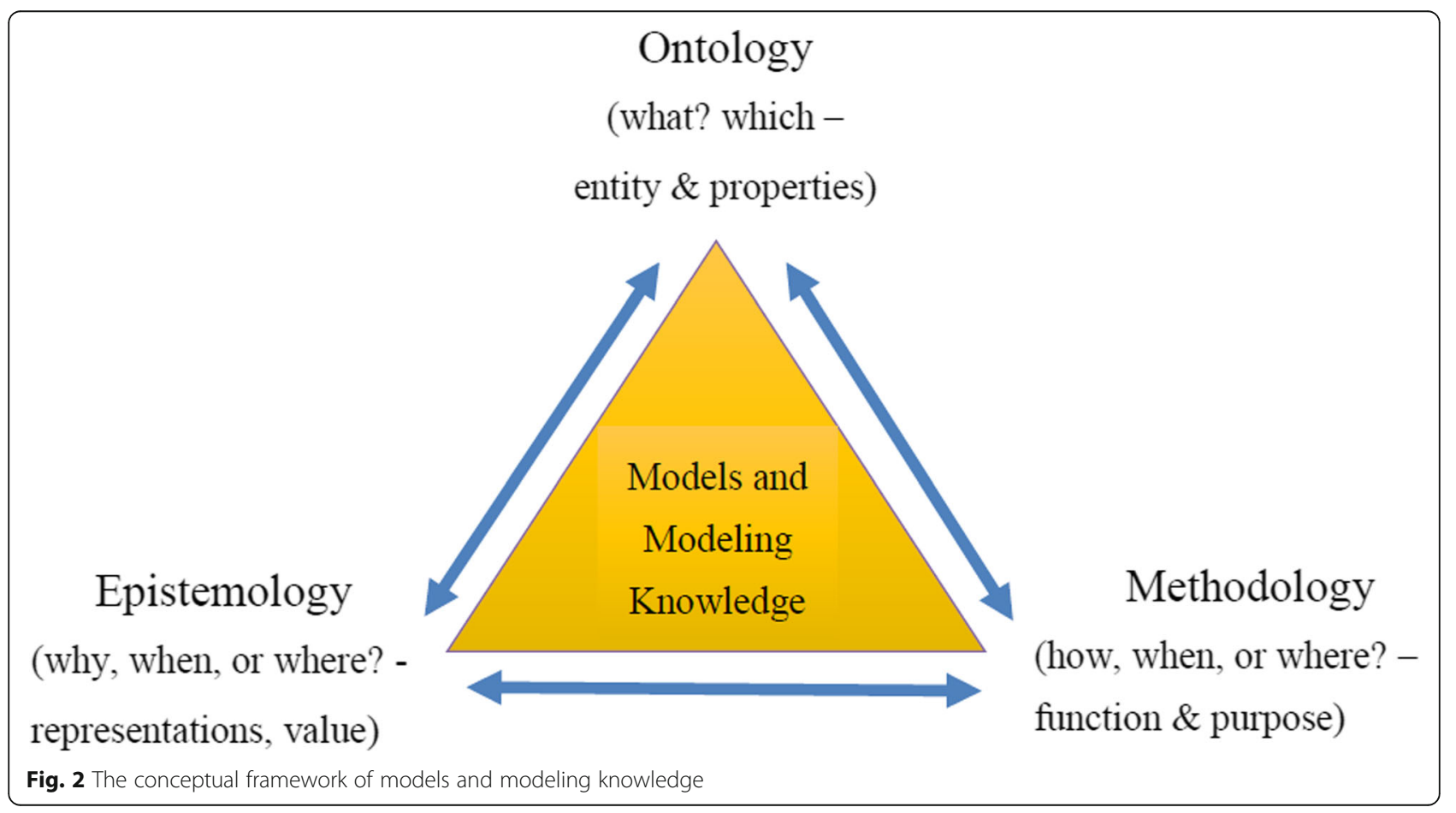


Many considered models to be intermediates between experimental actions and scientific theories. Formats of models can be scale, analog, iconic, symbolic, concrete, verbal, visual, mathematical, or theoretical (Giere et al., 2006; Gilbert, Boulter, \& Elmer, 2000; Harrison \& Treagust, 2000). Harrison and Treagust advocated other modes such as maps, diagrams, tables, simulations, and concept-process as models. In particular, models can be changed and/or replaced by another model that is better at predicting and explaining phenomenon (e.g., Grosslight et al., 1991). More importantly, models can be changed over time (Justi \& Gilbert, 2002). In sum, to better understand the nature of models, one has to understand the ontological entities (such as compositions, attributes, varieties, uncertainty, etc) in order to conceptualize what a model is trying to convey in terms of its meaning and relations between scientific theories, models, and the real world.

\section{Epistemological perspective}

Psychologists have mostly limited their work to how individuals conceptualize models and construct images of objects or rules (e.g., Gentner \& Smith, 2012; JohnsonLaird, 1983; Nersessian, 2008). Grosslight et al.'s (1991) classic work identified different levels of participants ranging from naive realists to scientific modelers. They also argued that students need more experiences in using models as intellectual tools, and more time to reflect upon the role of models in scientific inquiry. To extend the understanding of students' and teachers' perceptions of nature of models, various diagnostic tools based upon Grosslight's findings were developed, adopted, or investigated (e.g., Cheng \& Lin, 2015; Crawford \& Cullin, 2004; Lee, Chang, \& Wu, 2017; Park, Liu, Smith, \& Waight, 2017; Treagust et al., 2004; van Driel \& Verloop, 1999). A consistent finding about the perception of models was an emerging need of developing epistemological views of the nature of models, for both students and teachers in school science education.

Meanwhile, according to Johnson-Laird (1983), a mental model is a structural analogy of a real or imaginary situation relevant to problem-solving. Adapting JohnsonLaird's ideas, Nersessian (1999) argued that in scientific reasoning, mental models need to expand to models that are dynamic in nature due to the variability found across individual learners and across different contexts of phenomena. Human beings create models from both perception and description. Consequently, these constructive modeling processes rely on personal perceptions and experiences in a specific context.

Alternatively, Sins et al. (2009) investigated the relationships between students' cognitive processing, epistemological understanding of models, and modeling using computers. The research found a positive correlation between students' level of epistemological understanding and deep processing, and a negative correlation between students' level of epistemological understanding and surface processing. Gobert and Pallant (2004) also showed that students with more sophisticated epistemologies of models were better able to further their content understanding. It is claimed that students' understanding of the domain as well as their understanding of MMingK in science was improved by engaging them in an authentic context in which they were allowed to construct and reason with models. In addition, the multiple related aspects of a phenomenon might allow learners to construct their individual and unique understanding of scientific models and generate multiple possible models that might lead them to deeply understand scientific phenomenon and theories. The multiple representations of models might also expand learners' appreciation of scientific enterprise. Everett et al. (2009) claimed that "there is a specific purpose for the model that determines how it is constructed by the modeler and that the model no longer must exactly copy reality" (p.1220). However, the development of students' epistemological understanding of models takes effort and time for novices in science. Learners need to know why, when, and where the representations and values of models should be used to better understand scientific phenomenon.

We argue that modeling is a subjective meaningmaking process that requires active involvement. However, through negotiating with external information, concepts could become more tangible. Therefore, modeling can be creative and significant. Modeling is one form for conveying and constructing the ideas inherent in a given phenomenon in an authentic context.

\section{Methodological perspective}

Science is a process of constructing predictive conceptual models. This definition unites both the "processes" and the "product" of science (Gilbert, 1991, p. 73). Grosslight et al. (1991) advocated for developing curricula to facilitate students' conceptual change, talking explicitly with students about the nature of models, and enriching students' conceptions of the nature of models to facilitate student learning from models. Their effort focused on students' understanding of the nature and the purposes/functions of models, and the "modeling processes."

Several significant functions of models have been identified. Böttcher and Meisert (2011) described a theoretical model as a set of representations of a natural process that offers interpretations and predictions regarding natural phenomena. Other researchers have considered a theoretical model as a basis for developing and examining theoretical models (Harris, 1999), interpreting experimental results (Tomasi, 1988), developing explanations (Gilbert, Boulter, \& Rutherford, 1998), generating predictions 
(Justi \& Gilbert, 2002), or connecting data to questions, and making abstract entities visible (Francoeur, 1997). Böttcher and Meisert claimed that representations of models are essential tools for communicating and conversing about the scientific models underlying them. A good model externalizes and expresses learners' thoughts and helps them visualize and examine components of their theories (Jonassen, 2008). However, students rarely utilize model's higher level functions, such as using models to explain or predict observable phenomena (Grosslight et al., 1991).

For the modeling process, Berland et al. (2016) claimed engaging students in scientific practices and understanding what to do can push students to move beyond the rote modeling process and engage in purposeful model construction instead. Berland et al. also proposed a framework to enhance students' engagement of scientific practice. Experienced educators will adopt different modeling processes in different model- or modeling-based instruction. Details of various modeling processes will be discussed in the next section. This framework emphasizes students' epistemic goal for their knowledge construction work and their epistemic understandings of how to engage in that work in which knowing how, when, or where to use the functions and purposes of the models should be essential from this perspective (See Fig. 2).

\section{Claim 3: Providing a modeling-based scaffolding framework for meaningful and active authentic learning is to enhance student's engagement of scientific practice} As discussed earlier, before science educators started investigating the nature of models and modeling (MMingK), philosophers and psychologists had already examined their roles in developing science theories (Giere, 1988; Norman, 1983; Suppe, 1977). Modeling practice which was viewed as a way to construct knowledge in science education could be traced back to researchers in the 1980's (Clement, 1989; Halloun \& Hestenes, 1987; Hestenes, 1987). In the 1980s, these topics started receiving more and more attention by science educators, particularly in physics education (e.g., Halloun \& Hestenes, 1987). Then it became an important research topic and spread to other fields even though it was unclear whether there was a direct relationship or impact on the blooming research area of scientific models.

Starting in the 2000's, more studies were carried out on modeling processes in practice, and various definitions of modeling processes were proposed as a result. For instance, Justi and Gilbert (2002) presented a diagrammatic representation to depict modeling as a process in which a mental model is produced and expressed in any mode of representation. For Hestenes and Halloun, the use of the modeling approach is a pedagogical theory which is concerned with cognitive processes and curriculum. The teacher would discuss the organization of scientific knowledge during each modeling stage, and encourage students to employ modeling strategy when trying to solve problems in textbooks (Hestenes, 1987) or experimental activities (Halloun, 1996). As for Clement, Justi, and Gilbert, modeling is a vigorous tool to develop mental skills. During the modeling processes, researchers identified several steps, such as constructing, validating, applying, evaluating, and revising scientific models during modeling practice (e.g., Hestenes, 1987; Lehrer \& Schauble, 2003; Schwarz et al., 2009).

Inspired by Hestenes and Halloun's idea, the first author of this article proposed the DEAR cyclic model on modeling practice (Chiu, 2016; Chiu, 2018). This DEAR model integrated Justi and Gilbert's consideration of the scope and limitations for a model to construct a circulated process of modeling, that is model Development, model Elaboration, model Application, and model Reconstruction (Fig. 3). The aim of our DEAR cycle is to be a goal-oriented and competence-based scaffolding for designing, implementing, or evaluating efficient modeling-based instruction, model-based text (Jong, Chiu, \& Chung, 2015), and model-based assessment of students' products (Chang \& Chiu, 2009). In Fig. 3, the DEAR model does not only include the modeling processes, it has also taken students' learning outcomes (such as the initial models) into account.

Model- or modeling-based instruction often follows the modeling process to guide the instruction design. However, different variations on what is called the "modeling process" can be found throughout literature. For example, Schwarz and Gwekwerere (2007) used EIMA (Engage-Investigate-Model-Apply) as a modeling instructional framework to help preservice teachers incorporate model-centered scientific inquiry into their practices. Campbell, Oh, and Neilson (2014) followed the sequentially organized modeling pedagogies: expressive, experimental, evaluative, exploratory, and cyclic modelings. These different terms and sequences may confuse teachers and curriculum designers. One of the reasons for the diversity is that the goal scholars wanted to attain is different. For instance, Gilbert and Justi (2016) proposed five approaches to learning about models and modeling: learning curricular models; learning to use models; learning to revise models; learning to reconstruct models; and learning to construct a model de novo. In the former three approaches, students use existing models to learn science, and these three belong to model-based instruction. In the latter two approaches, students create or re-create models in a more authentic science environment, and these two belong to modelingbased instruction. In this view, Schwarz and Gwekwerere's EIMA framework is instructional scaffolding about model- 


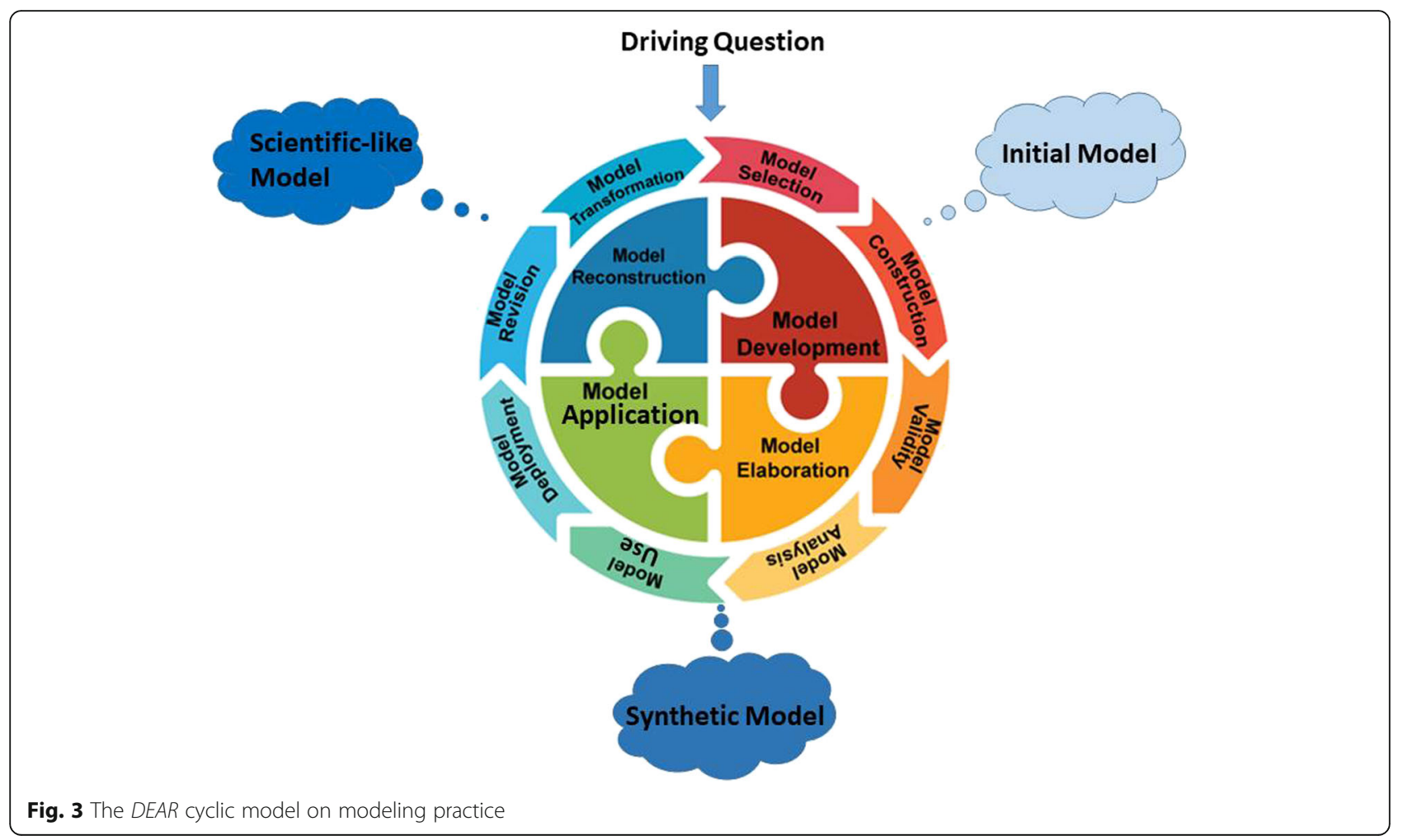

based instruction, while Campbell et al.'s organized modeling pedagogies and our DEAR cycle are modeling-based instruction. To clarify the language and scholars' goals, it could be helpful for educational practitioners to choose an appropriate instructional framework to scaffold their teaching in a more meaningful and active authentic way, and to enhance student's engagement of scientific practice accordingly.

Claim 4: Developing appropriate formative assessment instruments and evaluation rubrics is to assess students' modeling products within the context of modeling practice

Modeling product is critical for classroom practice not only because it is the outcome of science and science learning, more importantly, it makes students' thinking visible to teachers, their peers and themselves (Windschitl, Thompson, \& Braaten, 2008) by designing/drawing paper models (e.g., Bamberger \& Davis, 2013; Chung \& Chiu, 2012; Danusso et al., 2010) or creating computer models (e.g., Louca et al., 2011; Park et al., 2017; Sins et al., 2009) and so on. In addition, teachers can help students monitor how their thinking changes in response to new evidences and ideas.

Modeling product includes two variations: internal and external representations of the target models. Mental models are one kind of internal representations that share similar relation-structure to what is being represented. People constructed mental models to reason with, to explain, to make predictions about phenomena, and to solve problems involving them (Nersessian, 1999; Vosniadou, 1994). We cannot visualize someone's internal representation unless they are externalized.

How can we help students develop their competence on constructing and applying, even modifying, internal and external representations? We advocated integrating formative assessment technique into modeling practice in classroom to help teachers and students visualize the change in their thinking through the process of modeling practice. For example, Chung and Chiu (2012) designed a series of lesson plans consisting of eight 50-min teaching sessions about multiple representations and model for the teaching of ideal gas, and used concrete models (dynamic model of particle motion, lung breathing simulator), PowerPoint presentations, hands-on experiment, role play, computer simulation and so on to teach. It also used open-ended questions with drawing and interview to explore the students' ideal gas law mental models evolution before, during, and after instruction. The results showed positive effectiveness on students' construction of scientific model after modeling practice with multiple representations. It is worth mentioning that, in this study, formative assessment was adopted to observe students' evolution of mental model, in particular to focus on the elements (e.g., particle nature of matter) and the relations between elements 
(e.g., the incorrect relations, the larger the volume of gas particles, the greater the pressure) within students' mental model, so that teachers could adjust their teaching in response to students' alternative conceptions/models. Louca et al. (2011) observed an experienced teacher implementing modeling-based teaching in two science classrooms. All students used a computer programming environment, Stagecast Creator, as a modeling tool to develop models of physical phenomena, and the experienced teacher in this study adopted formative assessment to constantly assesse students' thinking and inquiry. The findings showed three modeling frames of students' discourse: phenomenological description, operationalization of the physical system's story, and construction of algorithms. These three modeling frames were not in sequence. Instead, a teacher can view modeling-based teaching as a balance between these three modeling frames, and can facilitate the balance within students' conversations.

Although formative assessment is critical to the implementation of classroom modeling practice, Nicolaou and Constantinou's (2014) study found most of the research on modeling competence conducted summative assessment rather than formative assessment to collect and analyze students' modeling product. Possible reasons might be lacking a framework to assess the quality of students' modeling products, time, and manpower needed to identify and diagnose the type of students' mental models during classroom practice. To extend the effectiveness of conceptual change research, developing appropriate instruments and evaluation rubric for formative assessment to assess the quality of students' modeling product is essential. With the assistance of technology, applying a web-based modeling product diagnosis and evaluation system in a science classroom is gradually becoming feasible. For example, our team developed the web-based mental models diagnosis system which provides a framework to help teachers diagnose students' mental models in various science topics (Wang, Chiu, Lin, \& Chou, 2013). Integrating a modeling competence framework (e.g., the modeling competence framework we proposed in this study), the web-based modeling product diagnosis and evaluation system will assist teachers to externalize students' modeling product and determine their quality in a science classroom.

\section{Claim 5: Research on learning progression in modeling competence needs to be intertwined with MMingK and modeling practice \\ Investigating the interaction between the two aspects of modeling competence}

LP depicts the development of students' knowledge and ability over time, and provides a better alignment between curriculum, instruction and assessment (Duncan \& Hmelo-silver, 2009). It is believed that the attainment of LP in modeling competence will be the intertwining of MMingK and modeling practice to pursue "successively more sophisticated ways of reasoning within a content domain that follow one another as students learn" (Smith, Wiser, Anderson, \& Krajcik, 2006, p. 1). However, until now, there had been no study that explored the interaction between these two aspects, let alone the design or discussion of a detailed structure of LP that includes these two aspects. Therefore, we suggest that the first step for designing LP of modeling competence would be investigating the interaction between these two aspects in varied topics at different educational stages. Since an LP that includes the two aspects of modeling competence has yet to be designed, we will discuss the design of these two aspects below.

\section{Designing an assessment for a holistic understanding of models and modeling knowledge}

Grosslight et al. (1991) identified some characteristics to discriminate participants' understanding of models and modeling from Level 1 (naïve) to Level 3 (scientific). Many scholars followed their idea and interview questions to develop related instruments on MMingK (e.g., Gobert \& Pallant, 2004; Sins et al., 2009); yet, most of the instruments on modeling assessment were domain general (Namdar \& Shen, 2015; Nicolaou \& Constantinou, 2014). Since we cannot discuss students' competence in modeling practice without a science context, it is worth to rethink if there is any difference between domain general and domain specific in MMingK.

We hope we have already provided a rationale for building a holistic framework for assessing MMingK in Claim 2. Due to the lack of a holistic and theoretical framework for assessing students' MMingK, we proposed an integrative model with ontology, epistemology, and methodology, and tested their usefulness in explaining and assessing students' MMingK. This instrument includes a 46-items multi-perspective framework (ontological: 15 items, epistemological: 15 items, methodological: 16 items). Compared to existing assessment instruments for MMingK (Namdar \& Shen, 2015; Nicolaou \& Constantinou, 2014), this instrument's reliability for high school students is high $(\alpha=.90)$. The higher-order confirmatory factor analysis (Chi-Square $=96.93, \mathrm{df}=33, p$-value $=0.00000$, RMSEA $=$ 0.070 ) result also validated the theoretical assumption of students' knowledge of models and modeling; the three perspectives was also confirmed to be important in this holistic model (Chiu, 2016). Although several studies developed instruments to measure participants' MMingK (e.g., Justi \& Gilbert, 2002; Treagust, Chittleborough, \& Mamiala, 2002; van Driel \& Verloop, 1999), there lacked a higher-order comprehensive framework to explain the phenomenon. Our framework moves the research on MMingK one step further and allows researchers to assess 
students' and teachers' perceptions of MMingK in a holistic manner.

\section{Designing an assessment of modeling practice to link modeling process and modeling product}

Students start to learn about models and modeling at very different points in time. If we can provide a representation to show the status of their relevant knowledge when they start to undergo that process, we can revisit the models and the context throughout the curriculum (Merritt, Krajcik, \& Shwartz, 2009). It would be very helpful for designing the LP of students' modeling product. However, most investigations of the modeling product simply show the percentage and the change of students' mental models in different grades or ages (e.g., Chung \& Chiu, 2012; Merritt et al., 2009). More detailed information about how the conceptions, factors and relations changed are not clear. Accordingly, a Conceptual Evolution Tree (CET) approach on analyzing students' mental models was developed to outline the evolutionary pathways of students' modeling products (Chiu \& Lin, 2008; Lin, 2006). This approach uses analogies between students' conceptual learning and evolutionary epistemology, biological evolution, and cladistics to create a theoretical foundation based on literature review and analysis. Specifically, this approach adopts the cladistics methodology to create an optimal hypothetical CET. CET provides a representation of the evolutionary pathways of students' mental models about a specific topic, and can be verified by cross-grade investigation or previous empirical studies. Several topics have been explored and validated by cross-grade investigation in our team, such as electric circuit (Lin, 2006, 2017), phase transitions (Chiu \& Wu, 2013), shape of the earth (Wu \& Lin, 2013), and ideal gas (Chiu, Wu, Chung, Li, \& P., 2013).

Although CET can provide the information of evolutionary pathways of students' mental model via a representation, it cannot show the interaction between modeling process and modeling products. Gilbert and Justi (2016, p. 203) recommended a strategy that entails "an explicit and progressive exposure to competence in modeling" to link the process and the product of modeling practices. The strategy starts with students linking concrete representations of phenomenon using a curriculum model. Our thinking for the LP of modeling practice is consistent with Gilbert and Justi's view. In 2009, our team (Chang \& Chiu, 2009) adopted the Structure of the Observed Learning Outcome (Biggs \& Collis, 1982) and the Scientific Theory Structure (Hempel, 1958) to develop and define six levels for different stages of modeling process. We named it Modeling Competence Analytic Index (MCAI). There are two axes in MCAI, one is modeling process, and the other is the complexity level of the constructed model. It is a $6 \times 6$ matrix in domain general to investigate students' progression of modeling product during the different stages of modeling process. We suggested the investigated results could be used to guide educators design LP in various science topics.

\section{Conclusions}

In this paper, we made five claims for promoting modeling competence in science learning. The five claims are (1) the development of modeling competence in practice is essential to scientific literacy for twenty-first century citizens, (2) further research is needed to build a holistic and theoretical understanding of models and modeling knowledge (MMingK), (3) providing a modeling-based scaffolding framework for meaningful and active authentic learning is to enhance student's engagement of scientific practice, (4) appropriate formative assessment instruments and evaluation rubrics to assess students' modeling processes and products within the context of modeling practice should be developed and (5) research on learning progression in modeling competence needs to be intertwined with MMingK and modeling practice. Each claim highlights the emerging needs for cultivating students' understanding of the nature of models and modeling, and put them into practice. The ideal learning outcomes of this modeling practice would not happen quickly, but we believe gradual improvement can be attained through well-planned instruction and welltrained teachers. To be able to effectively evaluate the outcome of modeling-based instruction, various forms and methods should be taken into consideration while assessing students' performance across grades. However, we have to alert teachers, who are the souls of successful education, to be aware of the need to develop modeling competence and pedagogical content knowledge for modeling, so as to be able to externalize what they expect the students to produce, and understand the purpose of modeling approach instruction.

\section{Abbreviations \\ CET: Conceptual Evolution Tree; DEAR cycle: A cyclic process of modeling, referring to model Development, model Elaboration, model Application, and model Reconstruction; EIMA: Engage-Investigate-Model-Apply; LP: Learning progression; MCAl: Modeling Competence Analytic Index; MMingK: Models and modeling knowledge; NOMs: Nature of models; RMSEA: Root Mean Square Error of Approximation}

\section{Acknowledgements \\ The authors would like to express their gratitude to the support by the Ministry of Science and Technology, Taiwan under the grant numbers (105-2511-S-003 -031 -MY3, 105-2628-S-259 -001 -MY3).}

\section{Authors' contributions}

The first author was in charge of the main structure of the article, abstract, introduction, claims $1 \& 2$, and concluding remarks. The second author was in charge of Claims 3, 4, and 5. However, both of us went through the entire article together several times to make sure the statements coherent and consistent. Both authors read and approved the final manuscript. 


\section{Funding}

Ministry of Science and Technology, Taiwan.

\section{Availability of data and materials}

Not applicable

\section{Ethics approval and consent to participate}

Not applicable

\section{Consent for publication}

Not applicable

\section{Competing interests}

The authors declare that they have no competing interests.

\section{Author details}

${ }^{1}$ Graduate Institute of Science Education, National Taiwan Normal University, 88 Sec 4, Ting-Chou Road, Taipei, Taiwan. ${ }^{2}$ Department of Science Education, National Taipei University of Education, No.134, Sec. 2, Heping E. Rd., Da-an District, Taipei City 106, Taiwan.

\section{Received: 17 April 2019 Accepted: 22 October 2019}

\section{Published online: 28 November 2019}

\section{References}

Adúriz-Bravo, A., \& Izquierdo-Aymerich, M. (2005). Utilizing the 3P-model to characterize the discipline of didactics of science. Science \& Education, 14 29-41.

Bamberger, Y., \& Davis, E. (2013). Middle-school science students' scientific modelling performances across content areas and within a learning progression. International Journal of Science Education, 35(2), 213-238.

Berland, L. K., Schwarz, C. V., Kirst, C., Kenyon, L., Lo, A. S., \& Reiser, B. J. (2016). Epistemologies in practice: Making scientific practices meaningful for students. Journal of Research in Science Teaching, 53(7), 1082-1112. https://doi.org/10.1002/tea.21257.

Biggs, J. B. \& Collis, K. F. (1982). Evaluating the quality of learning: The SOLO taxonomy. New York: Academic Press.

Böttcher, F., \& Meisert, A. (2011). Argumentation in science education: A modelbased framework. Science \& Education, 20(2), 103-140. https://doi.org/10. 1007/s11191-010-9304-5.

Campbell, T., Oh, P. S., \& Neilson, D. (2014). Reification of Five Types of Modeling Pedagogies with Model-Based Inquiry (MBI) Modules for High School Science Classrooms. In I. Management Association (Ed.), K-12 Education: Concepts, Methodologies, Tools, and Applications (pp. 401-421). Hershey, PA: IGl Global. https://doi.org/10.4018/978-1-4666-4502-8.ch024.

Chang, C. K., \& Chiu, M. H. (2009). The development and application of modeling ability analytic index - Take electrochemistry as an example. Chinese Journal of Science Education, 17(4), 319-342.

Cheng, M. F., \& Lin, J. L. (2015). Investigating the relationship between students' views of scientific models and their development of models. Intenational Journal of Science Education, 37(15), 2453-2475.

Chiu, M. H. (2016). Developing modeling theory and indicators to design modelingbased inquiry lessons - An investigation on scientific conceptual change and modeling abilities. Technical report to the Ministry of Science and Technology, Taipei, Taiwan.

Chiu, M. H. (2018). Connecting local action with global trend, bridging global trend with local action: Science Education Research and Practice. Paper presented at the 2018 International conference of east-Asian Association for Science Education, November 29-December 1, Hualian, Taiwan.

Chiu, M. H., \& Lin, J. W. (2008). Research on learning and teaching of students' conception in science: A cognitive approach review. In I. V. Eriksson (Ed.), Science education in the 21st century, (pp. 291-316). New York: Nova Science Publishers.

Chiu, M. H., \& Wu, W. L. (2013). A novel approach for investigating students' learning progression for the concept of phase transitions. Education Quimica [Special Issue on Learning Progressions in Chemistry], 24(4), 373-380.

Chiu, M. H., Wu, W. L., Chung, S. L., \& Li, S. P. (2013). Investigating students' mental models of ideal gas across grade levels via the conceptual evolutionary approach. Chinese Journal of Science Education, 21(2), 135-162.
Chung, S. L., \& Chiu, M. H. (2012). The evolution of the 11th graders' mental models of ideal gas. Journal of Research in Education Sciences, 57(4), 73-101.

Clement, J. (1989). Learning via model construction and criticism. In G. Glover, R. Ronning, \& C. Reynolds (Eds.), Handbook of creativity, assessment, theory and research, (pp. 341-381). New York: Plenum. https://doi.org/10.1007/978-14757-5356-1 20

Clement, J. J., \& Rea-Ramirez, M. A. (2008). Model based learning and instruction in science. vol 2. Dordrecht: Springer.

Crawford, B. A., \& Cullin, M. J. (2004). Supporting prospective teachers' conceptions of modeling in science. International Journal of Science Education, 26(11), 1379-1401.

Danusso, L., I. Testa, and M. Vicentini (2010). Improving prospective teachers' knowledge about scientific models and modelling: Design and evaluation of a teacher education intervention. International Journal of Science Education, 32(7), 871-905.

Develaki, M. (2007). The model-based view of scientific theories and the structuring of school science programmes. Science \& Education, 16, 725-749. https://doi.org/10.1007/s11191-006-9058-2.

Duncan, R. G., \& Hmelo-silver, C. E. (2009). Learning progressions: Aligning curriculum, instruction, and assessment. Journal of Research in Science Teaching, 46(6), 606-609. https://doi.org/10.1002/tea.20316.

Everett, S., Otto, C. A., Luera, G. R., et al. (2009). Preservice elementary teachers' growth in knowledge of models in a science capstone course. International Journal of Science and Mathematics Education, 7, 1201-1225. https:/doi.org/ 10.1007/s10763-009-9158-y.

Francoeur, E. (1997). The forgotten tool: The design and use of molecular models. Social Studies of Science, 27, 7-40. https://doi.org/10.1177/030631297027001002.

Gentner, D., \& Smith, L. (2012). Analogical reasoning. In V. S. Ramachandran (Ed.), Encyclopedia of human behavior, (2nd ed., pp. 130-136). Oxford: Elsevier.

Giere, R. N. (1988). Explaining science: A cognitive approach. Chicago, IL: University of Chicago.

Giere, R. N., Bickle, J., \& Maudlin, R. F. (2006). Understanding scientific reasoning (5th ed., ). Belmont: Thomson/Wadsworth.

Gilbert, J. K., Boulter, C., \& Rutherford, M. (1998). Models in explanations, part 1: Horses for courses. International Journal of Science Education, 20(1), 83-97. https://doi.org/10.1080/0950069980200106.

Gilbert, J. K., Boulter, C. J., \& Elmer, R. (2000). Positioning models in science education and in design and technology education. In J. K. Gilbert, \& C. J. Boulter (Eds.), Developing models in science education, (pp. 3-18). Dordrecht: Kluwer Academic. https://doi.org/10.1007/978-94-010-0876-1_1.

Gilbert, J. K., \& Justi, R. (2016). Modelling-based teaching in science education. Dordrecht, Netherlands: Springer.

Gilbert, S. W. (1991). Model building and a definition of science. Journal of Research in Science Teaching, 28(1), 73-80. https://doi.org/10.1002/tea.3660280107.

Gobert, J. D. (2000). A typology of causal models for plate tectonics: Inferential power and barriers to understanding. International Journal of Science Education, 22(9), 937-977. https://doi.org/10.1080/095006900416857.

Gobert, J. D., \& Pallant, A. (2004). Fostering students' epistemologies of models via authentic model-based tasks. Journal of Science Education and Technology, 13(1), 7-22. https://doi.org/10.1023/B:JOST.0000019635.70068.6f.

Grosslight, L., Unger, C., Jay, E., \& Smith, C. L. (1991). Understanding models and their use in science: Conceptions of middle and high school students and experts. Journal of Research in Science Teaching, 28(9), 799-822. https://doi.org/10.1002/tea.3660280907.

Halloun, I. A. (2004). Modeling theory in science education. Netherlands: Kluwer Academic Publishers.

Halloun, I. (1996). Schematic modeling for meaningful learning of physics. Journal of Research in Science Teaching, 33, 1019-1041. https://doi.org/10.1002/ (SICI) 1098-2736(199611)33:9<1019::AID-TEA4>3.0.CO;2-I.

Halloun, I. A., \& Hestenes, D. (1987). Modeling instruction in mechanics. American Journal of Physics, 55(5), 455-462. https://doi.org/10.1119/1.15130.

Harris, T. (1999). A hierarchy of model and electron microscopy. In L. Magnani, N. J. Nersessian, \& P. Thagard (Eds.), Model-based reasoning in scientific discovery (pp. 139-148). New York, NY: Kluwer Academic.

Harrison, A. G., \& Treagust, D. F. (2000). A typology of school science models. International Journal of Science Education, 22(9), 1011-1026. https://doi.org/10. 1080/095006900416884

Hempel, C. G. (1958). Fundamentals of concept formation in empirical science. In C. G. Hempel (Ed.), International encyclopedia of unified science: Foundations of the unity of science, (vol. 2, pp. 88-93). Chicago: University of Chicago Press. https://doi.org/10.2307/2964310 
Hestenes, D. (1987). Toward a modeling theory of physics instruction. American Journal of Physics, 55(5), 440-454. https://doi.org/10.1119/1.15129.

Johnson-Laird, P. N. (1983). Mental models. Cambridge: Harvard University.

Jonassen, D. (2008). Model building for conceptual change. In S. Vosniadou (Ed.), International handbook of research on conceptual change, (pp. 676-693). New York: Routledge.

Jong, J. P., Chiu, M. H., \& Chung, S. L. (2015). The use of modeling-based text to improve students' modeling competencies. Science Education, 99(5), 986-1018.

Justi, R. S., \& Gilbert, J. K. (2002). Modelling, teachers' views on the nature of modeling, and implications for the education of modelers. International Journal of Science Education, 24(4), 369-387. https://doi.org/10.1080/09500690110110142.

Koponen, I. (2007). Models and modelling in physics education: A critical reanalysis of philosophical underpinnings and suggestions for revisions. Science \& Education, 16(7-8), 751-773. https://doi.org/10.1007/s11191-006-9000-7.

Kuhn, T. S. (1996). The structure of scientific revolutions, 3rd ed., (p. X). Chicago: University of Chicago.

Lee, S. W. Y., Chang, H. Y., \& Wu, H. K. (2017). Students' views of scientific models and modeling: Do representational characteristics of models and students' educational levels matter? Research in Science Education, 47, 305-328.

Lehrer, R., \& Schauble, L. (2003). Origins and evolution of model-based reasoning in mathematics and science. In R. Lesh, \& H. M. Doerr (Eds.), Beyond constructivism: Models and modeling perspectives on mathematics problem solving, learning, and teaching, (pp. 59-70). Mahwah, NJ: Lawrence Erlbaum Associates.

Lin, J. W. (2006). Investigating the influences of different teaching-learning sequences in textbooks on students with different mental models of electricity from the perspective of conceptual evolution. Unpublished doctoral dissertation [in Chinese]. Taiwan.

Lin, J. W. (2017). A cross-grade study validating the evolutionary pathway of student mental models in electric circuits. EURASIA Journal of Mathematics, Science \& Technology Education, 13(7), 3099-3137.

Louca, L. T., \& Zacharia, Z. C. (2012). Modeling-based learning in science education: Cognitive, metacognitive, social, material and epistemological contributions. Educational Review, 64(4), 471-492. https:/doi.org/10.1080/00131911.2011.628748.

Louca, L. T., Zacharia, Z. C., \& Constantinou, C. P. (2011). In quest of productive modeling-based learning discourse in elementary school science. Journal of Research in Science Teaching, 48(8), 919-951. https://doi.org/10.1002/tea.20435.

Matthews, M. R. (2007). Models in science and in science education: An introduction. Science and Education, 16, 647-652.

Metcalf, S. J., Krajcik, J., \& Soloway, E. (2000). Model-it: A design retrospective. In M. J. Jacobson, \& R. B. Kozma (Eds.), Innovations in science and mathematics education, (pp. 77-115). Mahwah: Lawrence Erlbaum Associates.

Merritt, J., Krajcik, J., \& Schwarz, Y. (2009). Particle Model of Matter. Proceedings of the 8th international conference on International conference for the learning sciences-Volume 2,75-81. Publisher: International Society of the Learning Sciences.

Ministry of Education in Taiwan (2018) Curriculum standards for grades 1-12. Taipei: Ministry of Education.

Namdar, B., \& Shen, J. (2015). Modeling-oriented assessment in K-12 science education: A synthesis of research from 1980 to 2013 and new directions. International Journal of Science Education, 37(7), 993-1023. https://doi.org/10. 1080/09500693.2015.1012185.

Nersessian, N. (1999). Model-based reasoning in conceptual change. In L. Magnani, N. J. Nersessian, \& P. Thagard (Eds.), Model-based reasoning in scientific discovery, (pp. 5-22). New York: Kluwer Academic/Plenum.

Nersessian, N. J. (2008). Creating scientific concepts. Cambridge: MIT.

NGSS Lead States (2013). Next generation science standards: For states, by states. Washington, DC: The National Academies Press.

Nicolaou, C. T., \& Constantinou, C. P. (2014). Assessment of the modeling competence: A systematic review and synthesis of empirical research. Educational Research Review, 13, 52-73. https://doi.org/10.1016/j.edurev.2014.10.001.

Norman, D. (1983). Some observations on mental models, In D. Gentner, \& A. L. Stevens (Eds.), Mental models (pp. 7-14). New York, NY: Psychology Press.

Oh, P. S., \& Oh, S. J. (2011). What teachers of science need to know about models: An overview. International Journal of Science Education, 33(8), 1109-1130. https://doi.org/10.1080/09500693.2010.502191.

Park, M., Liu, X., Smith, E., \& Waight, N. (2017). The effect of computer models as formative assessment on student understanding of the nature of models. Chemistry Education Research and Practice, 18, 572-581. https:/doi.org/10.1039/C7RP00018A.

Pluta, W. J., Chinn, C. A., \& Duncan, R. G. (2011). Learners' epistemic criteria for good scientific models. Journal of Research in Science Teaching, 48(5), 486-511.
Schwarz, C. V., \& Gwekwerere, Y. N. (2007). Using a guided inquiry and modeling instructional framework (EIMA) to support preservice K-8 science teaching. Science Education, 91(1), 158-186. https://doi.org/10.1002/sce.20177.

Schwarz, C. V., Reiser, B. J., Davis, E. A., Kenyon, L., Ache'r, A., Fortus, D., ... Krajcik, J. (2009). Developing a learning progression for scientific modeling: Making scientific modeling accessible and meaningful for learners. Journal of Research in Science Teaching, 46(6), 632-654. https://doi.org/10.1002/tea.20311.

Schwarz, C. V., \& White, B. Y. (2005). Metamodeling knowledge: Developing students' understanding of scientific modeling. Cognition and Instruction, 23(2), 165-205.

Smith, C. L., Wiser, M., Anderson, C. W., \& Krajcik, J. (2006). Implications of research on children's learning for standards and assessment: A proposed learning progression for matter and the atomic-molecular theory. Measurement: Interdisciplinary Research and Perspectives, 4(1-2), 1-98.

Sins, P. H. M., Savelsbergh, E. R., van Joolingen, W. R., \& van Hout-Wolters, B. (2009). The relation between students' epistemological understanding of computer models and their cognitive processing on a modeling task. International Journal of Science Education, 31(9), 1205-1229. https://doi.org/10.1080/09500690802192181.

Sun, D., \& Looi, C. K. (2013). Designing a web-based science learning environment for modeling-based collaborative inquiry. Journal of Science Education and Technology, 22(1), 73-89. https://doi.org/10.1007/s10956-012-9377-9.

Suppe, F. (1977). The structure of scientific theories, (2nd ed., ). Urbana and Chicago: University of Illinois Press.

Taber, K. S. (2009). Progressing science education: Constructing the scientific research programme into the contingent nature of learning science (Vol. 37). Springer Science \& Business Media.

Tomasi, J. (1988). Models and modeling in theoretical chemistry. Journal of Molecular Structure, 179, 273-292. https://doi.org/10.1016/0166-1280(88)80128-3.

Treagust, D. F., Chittleborough, G., \& Mamiala, T. L. (2002). Students' understanding of the role of scientific models in learning science. International Journal of Science Education, 24(4), 357-368.

Treagust, D. F., Chittleborough, G., \& Mamiala, T. L. (2004). Students' understanding of the descriptive and predictive nature of teaching models in organic chemistry. Research in Science Education, 34, 1-20. https://doi.org/ 10.1023/B:RISE.0000020885.41497.ed.

van Driel, J. H., Bulte, A. M., \& Verloop, N. (2007). The relationships between teachers' general beliefs about teaching and learning and their domain specific curricular beliefs. Learning and Instruction, 17(2), 156171. https://doi.org/10.1016/j.learninstruc.2007.01.010.

van Driel, J. H., \& Verloop, N. (1999). Teachers' knowledge of models and modeling in science. International Journal of Science Education, 21, 11411153. https://doi.org/10.1080/095006999290110.

Vosniadou, S. (1994). Capturing and modeling the process of conceptual change. Learning and Instruction, 4(1), 45-69. https://doi.org/10.1016/0959-4752(94)90018-3.

Wang, T. H., Chiu, M. H., Lin, J. W., \& Chou, C. C. (2013). Diagnosing students' mental models via the Web-Based Mental Models Diagnosis system. British Journal of Educational Technology, 44(2), E45-E48. https:/doi.org/10.1111/j.1467-8535.2012.01328x.

Windschitl, M., Thompson, J., \& Braaten, M. (2008). Beyond the scientific method: Model-based inquiry as a new paradigm of preference for school science investigations. Science Education, 92(5), 941-967. https://doi.org/10.1002/sce.20259.

Wu, Y. L., \& Lin, J. W. (2013). Validating children's conceptual evolution tree of earth in a cross-grade study. Journal of Research in Education Sciences, 58(4), 133-163. https://doi.org/10.6209/JORIES.2013.58(4).05.

\section{Publisher's Note}

Springer Nature remains neutral with regard to jurisdictional claims in published maps and institutional affiliations. 